\title{
DA DISCRICIONARIEDADE À TEORIA DA DECISÃO: A CRÍTICA HERMENÊUTICA DO DIREITO E OS LIMITES DO POSITIVISMO JURÍDICO
}

\author{
Fabricio Carlos Zanin* \\ Paulo Sergio Weyl Albuquerque Costa ${ }^{*}$
}

\section{RESUMO}

O tema é discricionariedade nas teorias do positivismo antes e depois de Dworkin desde a crítica hermenêutica do direito e sua teoria da decisão. O problema é: há a possibilidade de uma teoria da decisão no positivismo, seja ele qual for, mantendo-se intactos os seus princípios metodológicos da descrição e da separação entre direito e moral? O objetivo é apresentar a crítica hermenêutica do direito e sua oposição à discricionariedade dos positivismos. A conclusão é a de que a crítica hermenêutica não é apenas negativa com relação aos positivismos, ela é também positiva e construtiva de uma teoria da decisão.

Palavras-chave: Positivismo jurídico. Discricionariedade. Hermenêutica jurídica. Teoria da decisão. Crítica hermenêutica do direito.

\section{FROM DISCRETION TO DECISION THEORY: THE HERMENEUTIC CRITIQUE OF LAW AND THE LIMITS OF LEGAL POSITIVISM}

\begin{abstract}
The theme is discretion in the theories of positivism before and after Dworkin since the hermeneutic critique of law and his theory of decision. The problem: is there the possibility of a theory of decision in positivism, whatever it may be, keeping intact its methodological principles of description and separation between law and morality? The objective is to present the hermeneutic critique of the law and its opposition to the discretion of positivisms. The conclusion is that hermeneutic criticism is not only negative in relation to positivisms, it is also positive and constructive of a decision theory.

Keywords: Legal positivism. Discretion. Legal hermeneutics. Decision theory. Hermeneutic criticism of the law.
\end{abstract}

\section{INTRODUÇÃO}

O tema do artigo é a presença da discricionariedade nas teorias do positivismo antes e depois de Dworkin a partir da crítica hermenêutica do direito e sua teoria da decisão. Discutem-se os fundamentos filosóficos da antiguidade, do medievo, da modernidade e da contemporaneidade, os modelos hermenêuticos, os positivismos e a teoria da decisão.

\footnotetext{
* Professor Efetivo na Universidade Federal do Norte do Tocantins - UFNT. Doutorando em Filosofia do Direito na Universidade Federal do Pará - UFPA. Rua da Tobasa, 1033, Dergo, Tocantinópolis - TO, CEP: 77900-000. Email: fabriciozanin@ gmail.com; Lattes: http://lattes.cnpq.br/3258935280144372; Orcid: http://orcid.org/00000003-1571-2716.

* Professor Associado da Universidade Federal do Pará - UFPA. Doutor em Direito na Pontifícia Universidade Católica - PUC/RJ. Rua Augusto Corrêa, 01, Guamá, CEP: 66075-110. Email: weylpaulo@gmail.com; Lattes: http://lattes.cnpq.br/4135075517359609; Orcid: http://orcid.org/0000-0002-8848-2950.
} 
O problema pode ser formulado assim: há a possibilidade de uma teoria da decisão no positivismo, seja ele qual for, mantendo-se intactos os seus princípios metodológicos da descrição e da separação entre direito e moral? Nossa hipótese é a de que o positivismo, juntamente com a modernidade e seu fundamento humanista (filosofia da consciêcia), não é capaz de dar conta do fenômeno jurídico na sua completude, deixando a interpretação reduzida à discricionariedade.

O objetivo geral é apresentar a crítica hermenêutica do direito e sua oposição à discricionariedade dos positivismos ao propor uma teoria da decisão que não apenas descreva como os juízes decidem, mas também e, sobretudo, digam como é que eles devem decidir. O referencial filosófico é o da hermenêutica (filosófica e jurídica) e a metodologia é a da fenomenologia hermenêutica.

Divide-se o artigo em cinco partes. Na primeira (2), apresenta-se a filosofia no direito, ou seja, os fundamentos filosóficos que servirão à crítica hermenêutica do direito no seu posicionamento contrário à discricionariedade dos positivismos. Na segunda (3), os modelos da hermenêutica jurídica são apresentados, juntamente com suas oscilações entre a metafísica clássica e a metafísica moderna. Na terceira (4), mostra-se a reação positivista (positivismos exclusivo, inclusivo e normativo) e suas diversas respostas às críticas da modernidade. Na quarta (5), a crítica hermenêutica do direito aparece junto com a apresentação dos paradoxos dos positivismos. Por fim, na quinta parte (6), apresenta-se a teoria da decisão proposta pela crítica hermenêutica do direito.

\section{A FILOSOFIA NO DIREITO}

Os manuais de direito, especialmente os de introdução ao direito, de filosofia do direito e de direito constitucional, mas não apenas, costumam, por uma questão didática, dividir a história em períodos. Eles totalizam quatro: antiguidade, idade média, idade moderna e contemporaneidade. Dependendo do manual e do (a) autor (a), os períodos podem variar na quantidade e na nomenclatura. Uns podem incluir a pré-história. Outros podem chamar a contemporaneidade de pós-modernidade. Serão adotados esses períodos para apresentar os fundamentos filosóficos de cada um deles e suas principais manifestações éticas, políticas e jurídicas (WOLKMER, 2008).

O fundamento filosófico da Grécia antiga é a natureza cosmológica. A palavra "cosmos" remete à ordem e perfeição naturais. O fundamento manifesta-se na ética, no direito 
e na política, que deveriam corresponder à ordem e à perfeição da natureza do cosmos. Assim, o ser humano deve seguir sua natureza racional, moral e política para ser feliz, captando as propriedades da natureza. Igualmente, o direito, para ser justo, deveria corresponder à natureza, daí o adjetivo "natural" do direito natural. E a "polis", ou seja, a organização política também, para ser justa, deve corresponder à ordem e à perfeição da natureza. $\mathrm{O}$ fundamento da natureza cosmológica une, numa totalidade, ética, direito e política, com destaque para as construções filosóficas de Sócrates, Platão e Aristóteles (GARCIA-ROZA, 1990).

O fundamento filosófico da Roma antiga é a natureza cosmopolita. Aqui, a natureza ganha um caráter mais imperial e expansivo. O fundamento cosmopolita manifesta-se na ética, no direito e na política. Na transição da Grécia para Roma, várias doutrinas éticas surgiram: epicurismo, estoicisno, dentre outras. Elas foram importantes para Roma e para o cristianismo primitivo. Já no direito, ganham destaque Cícero (GOYARD-FABRE, 1999), com suas obras filosóficas que transmitiram a tradição grega do direito natural para a nova cultura romana, e Justiniano, com seu famoso Código de Justiniano ("Corpus Juris Civilis"), que marca o nascimento da ciência jurídica. Na política, Roma era um império que, para sobreviver, deveria expandir-se através de guerras de conquista, concretizando seu fundamento cosmopolita (CALVO GARCIA, 1994).

O fundamento filosófico medieval é Deus. Da natureza cosmológica e cosmopolita, passa-se à natureza providencial e poderosa divina. Ela é que fundamenta a ética, o direito e a política. Numa complexa relação de filosofia grega, romana e judaísmo, o Deus pessoal e do amor cristão revoluciona a ética, o direito e a política. A ética torna-se uma ética do amor, que dá dignidade individual e ao próximo, todos irmãos, a partir do amor a Deus, Pai, Filho e Espírito Santo. O direito torna-se muito mais amplo do que direito natural e imperial, mas sim canônico, com fundamento na lei divina. E na política, a dimensão terrena dos impérios deve aprender a conviver com a dimensão espiritual e fundamental da Igreja. O caráter universal do império romano agora passa à Igreja. A teologia passa a fundamentar a filosofia e a ciência jurídica (GILSON, 2001).

O que une os fundamentos filosóficos antigo e medieval é o seu caráter objetivo, uma vez que a natureza (cosmológica, cosmopolita e divina) remete a algo externo, exterior, fora do sujeito, fundamentando-o em suas manifestações ética, política e jurídica. Na modernidade (ZANIN, 2018), pelas revoluções, isso muda. O novo fundamento filosófico é a natureza humana, racional e técnico-científica. A revolução protestante coloca o fundamento humano 
na ética. As revoluções burguesas colocam o novo fundamento na política, pelo liberalismo e contratualismo, e no direito, pelo positivismo e constitucionalismo. Ética, direito e política, antes unidos, agora estão separados pela visão humanista, racionalista, cientificista, positivista e técnica moderna. O sujeito passa a ser o fundamento de tudo, destacando-se os pensamentos de Descartes ("res cogitans"), Kant (eu transcendental) e Hegel (espírito absoluto) (GHIRALDELLI JÚNIOR, 2010).

O sonho moderno - de progresso, liberdade, riqueza e felicidade - transformou-se em pesadelo (TEIXEIRA, 2006). Heidegger (2001) usa a expressão "ontoteologia" para representar os fundamentos do pesadelo ocidental. Poderíamos completar a expressão assim: "ontoteotecnologia" (TATIÁN, 1997). O que isso significa? Significa toda a história ocidental e seus fundamentos filosóficos epocais em uma única palavra. $\mathrm{Na}$ antiguidade, o fundamento foi a ontologia da natureza cosmológica. No medievo, o fundamento foi a teologia da natureza divina. Na modernidade, o fundamento foi a tecnologia resultante da principal manifestação da racionalidade humana e do espírito moderno: as ciências e suas técnicas de controle/domínio do mundo natural e social (KAUFMANN, 1992).

Não apenas Heidegger criticou a modernidade. Muitos outros o fizeram: Schopenhauer, Freud, Nietzsche, Marx (HOTTOIS, 2008). Muitos outros movimentos o fizeram: existencialismo, filosofia da diferença, filosofia crítica, filosofia analítica, filosofia continental, teorias decoloniais, etc. (D'AGOSTINI, 2002) O que todas as críticas têm em comum é destacar as crises da modernidade. Dentre elas, as principais são: crise do sujeito, crise da razão, crise da metafísica, crise da ética, crise do estado, crise do direito, etc. (VATTIMO, 2005) Enfim, não apenas o fundamento entra em crise, mas todas as suas manifestações éticas, políticas e jurídicas. Outro ponto em comum na crítica é o caráter uno, excludente e violento do fundamento, desde os gregos até a modernidade (MACCUMBER, 1999), destacando-se construções contemporâneas no sentido de tornar o fundamento mais includente, plural e democrático (ZANIN; POLICARPO, 2014).

No entanto, nem só de coisas em comum vive a crítica da modernidade. A primeira disputa refere-se a chamar, ou não, a contemporaneidade de pós-modernidade, com a finalidade de destacar justamente todas as crises citadas anteriormente. A segunda disputa, em relação com a primeira, refere-se aos posicionamentos no interior da pós-modernidade. Três são os posicionamentos. O primeiro acredita que a pós-modernidade não chegou ao seu fim, devendo as teorias dar destaque ao que dela ficou incompleto: seu projeto humanista e emancipatório (HABERMAS, 2002). O segundo acredita que a pós-modernidade chegou ao 
seu fim, devendo ser todos seus ideiais, completos ou não, totalmente descartados (VATTIMO, 1996). Por fim, o terceiro posicionamento é o de que a modernidade radicalizou as características da própria modernidade (LIPOVETSKY; SERROY, 2001). A terceira disputa refere-se à filosofia da linguagem. Alguns críticos dão destaque à viragem linguística e outros não. Entre os que dão destaque, uns têm uma abordagem mais analítica e lógicocientífica da linguagem, já outros têm uma abordagem mais histórica e ontológico-filosófica (KUSCH, 1989).

Mas as disputas não ocorreram apenas na contemporaneidade. Elas estiveram presentes também nos outros períodos. Na antiguidade, a disputa entre, por um lado, Heráclito e Platão com Parmênides e, por outro, entre Sócrates, Platão e Aristóteles com os sofistas foram intensas (REALE; ANTISERI, 1995). Na idade média, as disputas, no interior da teologia, entre a patrística, a escolática e o nominalismo foram intensas (VILLEY, 2009). Na modernidade, a disputa, por um lado, entre iluminismo e romantismo e, por outro, entre racionalistas e empiristas, ademais das disputas religiosas, foram intensas (VATTIMO, 2004). Por óbvio, todas essas disputas estão presentes hoje, na contemporaneidade (FARALLI, 2006). Por isso neoplatônicos, neoaristotélicos, neotomistas, neopositivistas, etc. digladiam-se entre si, especialmente no campo de batalha da teoria e da filosofia do direito (WARAT; PEPÊ, 1996).

Todo esse relato histórico sobre os fundamentos filosóficos e suas manifestações éticas, políticas e jurídicas será muito útil na abordagem da hermenêutica jurídica (escolas e métodos), dos positivismos da ciência jurídica, da crítica hermenêutica do direito e da problematização hermenêutica dos positivismos e da discricionariedade. Se todo o ideal de cientificidade do direito está fundamentado na epistemologia moderna, então está em crise. Se todo o ideal teórico positivista do direito está fundamentado na filosofia política e na epistemologia modernas, então está em crise. Se o ideal metodológico da hermenêutica jurídica está fundamentado no método do racionalismo moderno, então está em crise. Tudo isso veremos a seguir.

\section{A FILOSOFIA NA HERMENÊUTICA JURÍDICA}

O objetivo do presente tópico é apresentar a hermenêutica jurídica com base em três modelos (VERBICARO, 2019), relacionando-os com o positivismo jurídico e com os fundamentos filosóficos do tópico anterior. Ver-se-á que os modelos debatem-se entre si com 
a relação sujeito e objeto, que é oriunda do fundamento humanista, racionalista, científico e técnico da modernidade. Aliás, todo o ideal metodológico da hermenêutica jurídica tem suas raízes na modernidade e no seu modelo de ciência, cujo centro é o tripé sujeito-objeto-método (STEIN, 2001). Assim, apresentam-se os modelos dedutivo, decisionista e discricionário e, dentro deles, vários exemplos de escolas da hermenêutica jurídica, bem como suas oscilações entre os extremos da objetividade e da subjetividade.

O modelo dedutivo reune uma visão específica do estado, da ciência jurídica, do sistema jurídico e da interpretação. Quanto ao estado, considerado substituto de Deus e resultado das revoluções liberais, o legislador é onisciente, onipotente e onipresente, o executivo cumpre a vontade do legislador e o judiciário é a "boca da lei". Quanto à ciência jurídica, vê a codificação como fenômeno fundamental jurídico, tratando o código, de um lado, como sistematizador do direito e, de outro, de modo lógico, dedutivo e abstrato. Com relação ao sistema jurídico, algumas características o definem: hierárquico, harmônico, unitário, completo, perfeito, fechado, simples, claro e exato. Diante de tudo isso, óbvio que a interpretação deveria ser fiel à lei, reproduzindo-a e aplicando-a de forma silogística (VERBICARO, 2019).

Três exemplos são reunidos no modelo dedutivo: escola da exegese francesa, jurisprudência dos conceitos alemã e o positivismo utilitarista inglês de Bentham. O primeiro, herdeiro dos glosadores que tratavam o código romano de Justiniano como "ratio scripta", é marcado pelo Código Civil Napoleônico de 1804, símbolo máximo da racionalidade humana. O segundo está situado no contexto da escola histórica e dos pandectas, que trataram o Código Civil Alemão de 1896 também como manifestação racionalizadora e sistematizadora do direito, com destaque para Savigny e Ihering. O terceiro, muito embora seja diferente dos demais por estar num contexto de common law e empirista, defende as qualidades da codificação, que deve ser tratada de forma positivista e utilitarista (LOSANO, 2011).

O modelo decisionista é o extremo oposto do modelo dedutivo, também reunindo visões específicas do estado, da ciência jurídica, do sistema jurídico e da interpretação. Quanto ao estado, há uma crise das fontes, pois o direito não é mais reduzido à lei que, sozinha, já não dá mais conta da complexidade de novos contextos sociais. Quanto à ciência jurídica, é uma reação ao modelo dedutivo, racionalista e formalista, substituindo as características do legislador pelas do juiz. Com relação ao sistema jurídico, a existência de lacunas e antinomias lógicas do sistema acaba por retirar dele as características de harmonia, 
completude, perfeição. Diante de tudo isso, a interpretação infiel da lei passa a ser autorizada, em nome da inovação e da adaptação da lei a novos contextos sociais (VERBICARO, 2019).

Quatro são os exemplos de escolas reunidas neste modelo, todos eles dando especial relevância ao juiz e ao judiciário. O primeiro é a livre investigação do direito, na qual está Geny, que defende uma interpretação em duas fases: primeiro subjetiva, da vontade do legislador expressa na lei, mas, depois, de livre investigação do juiz além da lei, chegando ao direito natural. O segundo é o direito livre, com destaque para Kantorowicz, que defende a interpretação feita pelo juiz de acordo com o contexto sociológico da lei e do intérprete. $\mathrm{O}$ terceiro é a jurisprudência dos interesses, e mais tarde dos valores, que defende o sentido teleológico das leis através da ponderação de seus interesses e valores, destacando-se Ihering em sua segunda fase. O quarto é o realismo jurídico, com seu sentido absoluto de discricionariedade do juiz diante da lei, em especial os autores Holmes e Ross (LOSANO, 2011).

O modelo discricionário é um meio termo entre o modelo dedutivo e o modelo decisionista. O modelo dedutivo é o extremo da objetividade, pois afirma que, em todos os casos, deve-se aplicar à interpretação da lei o procedimento objetivo do silogismo, sendo a discricionariedade, portanto, negada absolutamente. O modelo decisionista, por sua vez, é o extremo da subjetividade, pois afirma que, em todos os casos, deve-se aplicar na interpretação da lei o ceticismo com relação à mesma, sendo a discricionariedade, portanto, defendida na sua versão absoluta (VERBICARO, 2019). Várias versões do positivismo jurídico podem ser enquadradas no modelo discricionário. Entre elas, encontram-se Austin, Kelsen e Hart (BARZOTTO, 2004).

O positivismo utilitarista de Bentham foi desenvolvido e radicalizado pelo positivismo analítico de Austin. A fonte do direito é o poder estatal legislativo que, através de um comando mandamental soberano, coloca a norma de forma estadista e imperativista. A lei é a forma e o fundamento do direito. A fonte estatal do direito garante-lhe autonomia e cientificidade. O sistema jurídico é incompleto, pois a ordem direta do soberano não pode prever tudo, o que, indiretamente, acaba resultando, quanto à interpretação, na discricionariedade criativa e complementar dos juízes. Seja direta ou indiretamente, o direito é tido como um instrumento utilitarista e reformista governamental, capaz de gerar progresso SOcial (MORRISON, 2006).

O positivismo normativista de Kelsen é também um exemplo do modelo da discricionariedade. O monismo estatal kelseniano afirma que o estado só pode ser de direito e 
que o direito só pode ser estatal. Nesse sentido, com sua herança neopositivita lógica, aplica ao objeto direito o método da pureza lógica e seus dualismos (ser e dever ser, descrição e prescrição). O principal conceito da ciência jurídica é o de norma jurídica, entendida de forma isolada e em conjunto, formando o sistema jurídico, que é hierárquico, unitário e completo. Tais características são garantidas pela norma fundamental hipotética e transcendental. Lacunas e antinomias não existem no sistema, mas a discricionariedade é permitida dentro da moldura da norma jurídica (MORRISON, 2006).

O positivismo de Hart é crítico de seus antecessores Austin e Kelsen. Para compreender o direito, é necessária uma análise linguística aliada à análise sociológica. Assim, a norma jurídica recebe as características de textura aberta, vagueza, ambiguidade e zonas de penumbra. O lado sociológico ganha relevo na substituição da norma fundamental kelseniana pela regra de reconhecimento, mas mantém seus criérios de análise dualistas (ser e dever ser e descrição e prescrição). Na interpretação, o modelo de Hart representa o meio termo entre dedutivo e decisionista, pois, nos casos fáceis, aplica-se a dedução e, nos casos difíceis, aplica-se a discricionariedade, permitindo a utilização de recursos extrajurídicos (MORRISON, 2006).

Estado, direito, positivismo e hermenêutica jurídica são construções modernas e, como tais, marcadas pelo fundamento moderno. A modernidade, pela primeira vez, enfrentou o caráter objetivo dos fundamentos filosóficos antigo e medieval. O problema é que, no modelo dedutivo, predomina a visão da lei como um conceito com essências e propriedades objetivas, lembrando a herança objetiva dos fudamentos antigo e medieval. Já no modelo decisionista, nega-se a objetividade da lei para ressaltar a sua subjetividade decisionista. Assim, o modelo discricionário, marca de vários positivismos, fica no meio dessa relação sujeito-objeto e, seja absoluto ou não, o recurso à discricionariedade pelas teorias positivistas marca seu déficit histórico - assim como o da modernidade - no tratamento da interpretação e da decisão.

\section{A FILOSOFIA NA CIÊNCIA JURÍDICA}

Os positivismos de Bentham, de Austin, de Kelsen e de Hart podem ser complementados com a classificação de Bobbio a respeito dos positivismos metodológico, teórico e ético, como veremos abaixo. O que todos eles têm em comum? O seu fundamento moderno da natureza humana racional, científica e técnica e seu modelo de ciência. O que 
aconteceria com os positivismos se a modernidade entrasse em crise e fosse questionada em seus fundamentos? Ver-se-á que Dworkin representa uma crítica aos fundamentos do positivismo e que, após essa crítica, o positivismo se esgotou como teoria dominante jurídica, mas ressurgiu, amadureceu e renovou-se com os positivismos inclusivo, exclusivo e normativo.

Bobbio (1995) classifica o positivismo de três formas: metodológico, teórico e ideológico. O positivismo metodológico é dualista, pois aqui estão os principais dualismos positivistas: ser e dever ser, real e ideal, direito e moral. Além disso, o direito é visto como um fato social, desde sua positividade e faticidade, respeitando o modelo de ciência da modernidade, para o qual a neutralidade, relatividade e ceticismo morais devem ser elementos respeitados. $\mathrm{O}$ positivismo teórico é monista, legalista e formalista. $\mathrm{O}$ direito tem como fonte o estado. O direito tem sua manifestação na lei estatal, analisada formalmente. E o sistema jurídico é completo (lacunas, antinomias e discricionariedade), coerente (dinamicidade, antinomias e discricionariedade) e unitário (norma fundamental, de reconhecimento e discricionariedade). Por fim, o positivismo ideológico ou ético, o qual defende o dever absoluto e incondicional de obediência à lei estatal como moralmente boa.

Os positivismos de Bentham, de Austin, de Kelsen, de Hart e seus pressupostos metodológicos, teóricos e éticos destacados por Bobbio entraram em crise juntamente com a modernidade. Isso quer dizer que o fundamento moderno do positivismo, seja ele de qual versão for, está sendo duramente questionado e criticado. O pensamento de Dworkin representa essa crítica aos pressupostos fundamentais modernos do positivismo jurídico. A resposta a esses ataques e especialmente às críticas de Dworkin fez aparecer as divesas teorias contemporâneas do positivismo: inclusivo, exclusivo e ético-normativo.

O positivismo inclusivo pode ser chamado também de positivismo moderado ou "soft". Tem esse nome em razão de ver a tese da separação entre direito e moral de uma nova forma, diferente do positivismo anterior, de Bentham, Austin, Kelsen e Ross. Essa visão diferente do positivismo inclusivo sobre a relação entre direito e moral diz que os dois não têm uma conexão necessária, mas que ela pode, contingencialemente, acontecer ou não. Assim, critérios morais podem fazer parte do direito e a moral pode intervir tanto na validade, quanto na interpretação do direito. Ele reconhece, portanto, a valoratividade da prática jurídica. A moral pode ser incluída nos fundamentos das leis, interferindo na descrição teórica do direito (VERBICARO, 2019; STRECK, 2017d). 
Se a conexão entre direito e moral proposta pelo positivismo inclusivo não é necessária, podendo acontecer ou não, fica a pergunta: quando e como isso ocorre? $\mathrm{O}$ legislativo, o judiciário e o costume das práticas jurídicas é que podem fazer, ou não, essa conexão. No caso do legislativo, as leis é que podem ou não expressar critérios e juízos morais. No caso do judiciário, são os juízes que escolhem - a partir da discricionariedade — realizar ou não a incorporação. E os costumes das práticas jurídicas também podem ou não realizar a aproximação entre direito e moral. Seja qual for o caso, a aproximação entre direito e moral, a partir de agora, será feita de modo contingente e não necessário. Trata-se, portanto, de uma forma de conciliar, de forma inclusiva contingente, os princípios morais com a tese da separação. Os principais autores do positivismo inclusivo são: Herbert Hart, Jules Coleman, Mattew Kramer, Kenneth Himma, Wilfrid Waluchow, dentre outros (VERBICARO, 2019; STRECK, 2017d).

Ao lado do positivismo inclusivo, temos o positivismo exclusivo. Como o próprio nome já indica, ele não aceita as concessões e aberturas, mesmo que contingentes, que o positivismo inclusivo faz com base na teoria da separação entre direito e moral. A moral deve ser excluída do direito, mantendo a radicalidade da separação entre direito e moral. A validade e identificação do direito são independentes de critérios morais, pois, se o direito porventura incorporasse critérios morais, deixaria de ser direito. Se, por um lado, o positivismo inclusivo aceita uma teoria da decisão judicial como parte integrante de uma teoria descritiva do direito, por outro lado, o positivismo exclusivo nega tal possibilidade, alegando que a decisão é irrelevante para a descrição do direito (VERBICARO, 2019; STRECK, 2017d).

O positivismo exclusivo afirma que a determinação do que é e do que não é direito deve ser feita única e exclusivamente por critérios de legalidade, com exclusão da possibilidade da moral determinar ou corrigir o direito. A única forma de manter a autoridade legal é reconhecer a origem fática, empírica, social e convencional do direito. No entanto, os juízes utilizam, com base numa discricionariedade forte, critérios morais que, para o positivismo exclusivo, são vistos como critérios extrajurídicos. Mesmo com a utilização pelos juízes da discricionariedade forte apelando a critérios extrajurídicos, os critérios de identificação e validadação do direito não seriam afetados e nem desconfigurados. Os principais autores do positivismo exclusivo são: Joseph Raz, Andrei Marmor, Scott Shapiro, dentre outros (VERBICARO, 2019; STRECK, 2017d). 
O positivismo normativo ou ético afirma que absolutamente nenhuma definição ou descrição do direito é moral ou politicamente neutra. Isso quer significar que, para o positivismo normativo, há uma quebra do dualismo positivista tradicional entre descrição e prescrição. Por isso, uma teoria positivista deve ser não apenas descritiva, mas também e fundamentalmente prescritiva. Assim, o direito deve defender uma postura normativa moral e política, baseada num ideal procedimental de cidadania e de democracia, cujos valores aproximam direito e moral. Entretanto, essa aproximação entre direito e moral se dá apenas para identificar o direito, pois, na jurisdição, não é e nem deve ser imprescindível a moral para aplicação do direito. Mesmo assim, tal aproximação direito e moral pode ser feita pelos juízes (VERBICARO, 2019; STRECK, 2017d).

Quanto à interpretação, se os critérios de validade do direito dependem unicamente de fatos sociais, sem a presença de argumentos morais, isso quer dizer que os juízes devem defender a legitimidade da lei, excluindo seus critérios pessoais. Ademais, desacordos morais que causam conflitos sociais exigem a separação entre direito e moral na jurisdição, sob pena de ser procrastinada a discussão jurídica e a solução pacífica dos conflitos (VERBICARO, 2019; STRECK, 2017d).

Portanto, os juízes devem preservar a autoridade e a dignidade do legislador e da legislação - como respeito à democracia - no momento da interpretação. O positivismo jurídico normativo ou ético defende uma teoria da interpretação judicial limitada à fidelidade à lei e à democracia, mas, em alguns momentos, juízes podem exercer seu poder interpretativo discricionário. Seus principais autores são: Jeremy Waldron, Gerald Postema, Tom Campbell, dentre outros (VERBICARO, 2019; STRECK, 2017d).

Seja na sua versão anterior às críticas de Dworkin, seja na sua versão posterior às mesmas críticas, uma pergunta fica: será que, diante de tantas versões do positivismo, ele conseguiu romper com seus fundamentos modernos metodológico, teórico e ético? Será mesmo que pode se chamar essas "novas" versões de novas? Será que não se aplica ao positivismo a mesma coisa da modernidade, ou seja, será que o "pós"-positivismo e a "pós"modernidade conseguiram romper com seus fundamentos modernos? Será que existe um elemento em comum que unifique todas essas versões do positivismo? Será que, se relacionarmos todas essas versões com os fundamentos filosóficos da primeira parte, não conseguiremos chegar a tal elemento comum? É o que veremos agora.

\section{A CRÍTICA HERMENÊUTICA DO DIREITO}


O objetivo do presente tópico é relacionar todas as partes anteriores ao apresentar a matriz filosófica que fundamenta a crítica hermenêutica do direito e seus posicionamentos a respeito do positivismo, unindo os fundamentos filosóficos, os modelos hermenêuticos e os positivismos exclusivo, inclusivo e normativo. A radicalidade da crítica hermenêutica do direito encontra-se em sua base filosófica, que lhe permite ter uma visão mais ampla da ciência jurídica, em especial dos elementos comuns de todos os positivismos, seja nas suas versões antes de Dworkin, seja nas posteriores. O resultado dessa visão será avançar onde o positivismo tem dificuldade, o déficit e o reducionismo: a teoria da decisão.

A crítica hermenêutica do direito tem esse nome justamente porque tem um posicionamento crítico com relação a um determinado tipo de compreensão do direito. Seu referencial teórico vem do paradigma filosófico da hermenêutica (SCHMIDT, 2012). O tipo de compreensão do direito criticado é o chamado "senso comum teórico dos juristas" (WARAT, 1993), composto por um imaginário positivista (STRECK, 2014) interiorizado desde os bancos da graduação até a prática profissional, passando pela pós-graduação, exames de ordem e concursos públicos. Há uma mistura, em tal imaginário, consciente ou inconscientemente (PHILIPPI, 2001), de várias escolas e métodos da hermenêutica jurídica e de vários fundamentos filosóficos, o que gera uma crise de compreensão e de coerência do fenômeno jurídico.

A crítica do direito é hermenêutica porque fundamentada no paradigma filosófico da hermenêutica, sobretudo na filosofia hermenêutica de Heidegger (2003) e na hermenêutica filosófica de Gadamer (1998). Por ser filosófico, o paradigma da hermenêutica tematiza uma dimensão fundamental pré-científica, anterior à epistemologia e à relação sujeito-objeto, que é condição de possibilidade e de existência das próprias ciências. Assim, a dimensão hermenêutica é ontológica, anterior, prévia, constitutiva, fundante, fundamental, estruturante, que une transcendental e existencial. Portanto, a crítica hermenêutica do direito é um modo de compreender a positividade do direito indo além e superando os dualismos presentes nas metafísicas clássica e moderna (WARAT, 2000).

Amparar-se no paradigma da hermenêutica é força, mas também pode ser a fraqueza da crítica hermenêutica do direito (STRECK, 2017). Para explicar isso, vamos usar a metáfora de dois andares de uma casa (STEIN, 2002). No primeiro andar, está a hermenêutica, a dimensão histórica, a (pré) compreensão e o "como hermenêutico" (algo como algo) nas interpretações de si mesmo, dos outros e do mundo (STEIN, 2001). No segundo andar, está a 
analítica, que dá ênfase às análises lógicas e conceituais. Exemplos das diferenças das abordagens pode ser o conflito entre continentais e analíticos na filosofia ou, no direito, entre substancialistas e procedimentalistas. Estar no primeiro andar filosófico pode ser uma força, mas também uma fraqueza, a depender de como seja feita a relação com as ciências.

A força da crítica hermenêutica do direito está em, fundamentada no paradigma filosófico hermenêutico, fazer uma leitura muito peculiar dos positivismos, relacionando-os com seus fundamentos filosóficos. Assim, busca identificar, a despeito das variações do positivismo, seus elementos comuns, ou seja, compreender o substrato filosófico do positivismo e que de alguma forma aparece em todas as suas expressões historicamente situadas. Se o direito, sozinho, não é capaz de pensar a si mesmo, então a crítica hermenêutica do direito traz os fundamentos da filosofia para o direito, dando-lhe uma nova visão, diferente, mais ampla e completa. Desse modo, os elementos em comum de todos os positivismos são: discricionariedade, descrição analítica, relativismo, não saber o que fazer com a moral, etc. (STRECK, 2017).

Com base nesses elementos em comum a todos os positivismos, a crítica hermenêutica do direito começa a identificar vários paradoxos nos positivismos. O primeiro deles é do positivismo exclusivo. Se, por um lado, o positivismo exclusivo elaborou uma teoria da autoridade muito útil para o fortalecimento do respeito à lei, por outro lado, o juiz pode deixar de apresentar razões de autoridade em suas decisões de razão prática, decidindo à revelia do próprio direito. Há, portanto, uma forte presença dos dualismos ser e dever ser, descrição e prescrição, direito e moral e teoria do direito e teoria da decisão. Não há relação entre os raciocícios teóricos e os raciocínios práticos no direito (STRECK, 2017b).

O segundo paradoxo também é do positivismo exclusivo. Mantendo rígidas as separações metodológicas dualistas (ser e dever ser, descrição e prescrição, direito e moral), o positivismo não consegue dar conta da inteireza do fenômeno jurídico, deixando de fora a interpretação, relegada à discricionariedade. Assim, o paradoxo seria, por um lado, a racionalidade de identificação do direito, mas, por outro, a irracionalidade de sua aplicação interpretativa. A teoria do direito não se resume ao debate metodológico, exigindo, do positivismo, posicionamentos sobre a teoria da decisão. De outra maneira: até que ponto o positivismo pode abrir-se à decisão mantendo intactos seus princípios descritivos e a separação entre direito e moral? (STRECK, 2017b)

O terceiro paradoxo refere-se ao positivismo inclusivo. Seu nome é inclusivo porque pretende incorporar a moral no direito. Como é feita tal incorporação? Ela é feita de forma 
irracional relativista, ou seja, discricionariedade. Assim, de tanto querer fugir do positivismo exclusivo, acaba atirando-se na antítese voluntarista, correndo o risco de não mais poder ser a teoria chamada de positivista. Isso porque a abertura moral derruba o fechamento metodológico (ser e dever ser, descrição e prescrição, direito e moral). Se o direito não é algo dado, mas, sim, resultado de valores externos à lei, então os fundamentos positivistas ainda estão presentes? (STRECK, 2017b)

O quarto paradoxo é do positivismo normativo e remete às mesmas dificuldades citadas. Se o positivismo precisa ser descritivo para se sustentar, mantendo intacta a separação direito e moral, então, no positivismo normativo, ao aceitar, mesmo que em alguns casos, o uso da moral nas decisões, a separação já se torna problemática. Partindo-se do pressuposto da crítica hermenêutica do direito de que é absolutamente indispensável que uma teoria do direito seja normativa e que se construa uma teoria da decisão, então o positivismo normativo não é capaz e, se for, já não será mais positivismo. Portanto, o positivismo normativo também acaba muito próximo das outras versões do positivismo (STRECK, 2017b).

A principal conclusão a que chegamos neste tópico é a de que os elementos em comum dos positivismos são os responsáveis pelo senso comum teórico dos juristas. Descrição teórica para identificar o direito, neutralidade, relativismo e ceticismo quanto aos valores e separação radical entre direito e moral acabam sendo úteis, na ciência do direito, em sua parte dogmática, resultando no extremo da objetividade, mas, na teoria da decisão, acaba na discricionariedade, resultando no extremo da subjetividade. A crítica hermenêutica não é epistemológica (sujeito, objeto, método), mas sim ontológica (dimensão fundamental existencial), superando os dualismos dos fundamentos antigos, medieval e modernos e os paradoxos do positivismo ao propor uma teoria da decisão, como veremos.

\section{A CRÍTICA HERMENÊUTICA DO DIREITO E SUA TEORIA DA DECISÃO}

A concepção da crítica hermenêutica do direito é prescritiva e normativa, pois parte do princípio de que a função da doutrina é realizar "constrangimentos epistêmicos" (STRECK, 2017b) à jurisprudência, no sentido de determinar como os juízes devem decidir e como devem ser os critérios de avaliação e previsão de uma decisão. O judiciário não pode continuar o "vale-tudo" hermenêutico e o mix teórico de fundamentos clássicos e modernos presentes na realidade brasileira. Diante desse cenário, a crítica hermenêutica do direito 
oferece uma teoria da decisão composta de vários critérios de como uma decisão deve ser para ser considerada legítima e evitar o senso comum teórico e a discricionariedade.

Por ser importante na crítica aos positivismos e também na teoria da decisão proposta pela crítica hermenêutica do direito, apresenta-se o direito como integridade de Dworkin (2014) a partir das três fases do processo interpretativo (VERBICARO, 2019). A primeira é a fase pré-interpretativa, na qual ocorre a identificação do que seja direito, isto é, das normas da prática jurídica de uma determinada comunidade que, antes de serem incertas e arbitrárias, permitem, pelo contrário, o controle da decisão do juiz.

A segunda é a fase interpretativa, na qual, no presente, o intérprete se relaciona tanto com o passado, quanto com o futuro. Na sua relação com o passado, o intérprete deve posicionar-se de modo a concordar de forma adequada e consistente com o direito préexistente. Já na sua relação com o futuro, o intérprete pode, justificando-se com base nos princípios da justiça e da equidade, posicionar-se de modo a distanciar-se do direito préexistente. Seja na forma de concordância, seja na forma de discordância, o intérprete está em busca da melhor fundamentação moral e política da prática jurídica.

A terceira é a fase pós-interpretativa, na qual, sempre que o intérprete questionar ou reformar a prática jurídica pode fazê-lo com o dever de respeitar a coerência e a integridade da mesma, daí a metáfora da narratividade do romance em cadeia tão famosa do autor. Em suma, todo o processo interpretativo no seu conjunto (três fases), enseja um equilíbrio entre as tradições pré-interpretativas, interpretativa e pós-interpretativa, permitindo uma resposta correta, coerente e adequada, sem discricionariedade e sem elementos extrajurídicos.

Ao exemplificar sua hermenêutica filosófica com o historiador mais contemplativo, com o jurista mais prático e com o juiz que mais decide causas, Gadamer (1998) utiliza o conceito de aplicação para sintetizar o modo pelo qual todos eles, a partir da consciência histórica, se relacionam com a tradição. A experiência hermenêutica da consciência histórica une os dois momentos em que todos eles, na atualidade do presente, relacionam-se com a história do passado. Bem no meio, na mediação, é onde Hermes habita (ZANIN; COSTA, 2019). Então, a experiência de reconhecer e de apropriar-se de uma tradição (passado) está junto com a de questionar ou romper a mesma tradição. Assim, a interpretação nada mais é do que aplicação, ou seja, participação no "fórum da tradição", do qual todos fazem parte, exatamente como no processo interpretativo de Dworkin.

O que a crítica hermenêutica do direito faz, com base em Heidegger, Gadamer e Dworkin, é ser vigilante e constantemente lembrar a "hybris" da discricionariedade de que há 
um constrangimento que a tradição estabelece. Faz isso com base em três conceitos fundamentais do pensamento heideggeriano: situação hermenêutica, diferença ontológica e círculo hermenêutico (STEIN, 2000). A situação hermenêutica é composta da (pré) compreensão, com sua visão prévia, ter prévio e conceitos prévios. A diferença ontológica é a respeito do ser e do ente, isto é, que o ser só é ser de um ente e que o ente só é no seu ser, sem possibilidade de separação, como nas metafísicas clássica e moderna. O círculo hermenêutico decorre da diferença ontológica, pois o sentido do ser só se dá, acontece e se manifeta no ente e o sentido do ente só se dá, acontece e se manifesta no ser.

O "vale-tudo" hermenêutico, estado de natureza hermenêutico ou estado de exceção hermenêutico (ZANIN; COSTA, 2019) são a negação de todos os limites da comprensão e da interpretação expressos nos pensamentos de Dworkin, Gadamer, Heidegger e da crítica hermenêutica do direito. O senso comum teórico positivista dos juristas é o responsável pela reprodução "vale-tudo" do estado de natureza e de exceção hermenêuticos. E tal reprodução se dá a partir dos álibis da discricionariedade, que são: ponderações, livre convencimento, livre apreaciação de provas, discricionariedade sem arbitrariedade, etc. A palavra "livre" deveria ser abolida da teoria do direito e da decisão jurídicas, pois traz os fantasmas da metafísica da subjetividade moderna (STRECK, 2017c; STRECK, 2018).

Complementando as ideias anteriores, Rohden (2021) apresenta as características do chamado "eu hermenêutico", com base no paradigma hermenêutico (PALMER, 1989), em especial Gadamer. Suas caraterísticas são nove e que, ao fim e ao cabo, cumprem a mesma função: limitar o "vale-tudo" do estado de natureza e de exceção hermenêuticos: (1) abrir-se ao outro e à tradição; (2) acolher e respeitar o outro; (3) deixar o outro lhe dizer algo e ouvir; (4) diálogo com o outro, que pode ter razão; (5) deixar-se afetar e sensibilizar pelo outro, que pode mudar sua vida; (6) disposição a deixar valer algo diferente e estranho ao seu horizonte; (7) humildade e respeito à finitude; (8) implicações éticas, políticas e jurídicas do diálogo para a amizade e para a comunidade (9) exemplos do ecumenismo e do ecologismo como desejo e projeto de construir novas compreensões da tradição.

Outro exemplo de implicação jurídica seria a teoria da decisão proposta na crítica hermenêutica do direito para enfrentar o senso comum teórico positivista da discricionariedade e o "vale-tudo" do estado de natureza e de exceção hermenêuticos. O juiz deve, primeiro, examirnar as seis hipóteses pelas quais pode deixar de aplicar uma lei, se for o caso; segundo, fazer as três perguntas fundamentais; e, terceiro, examinar tudo isso à luz dos cinco princípios ou padrões interpretativos fundamentais. As seis hipóteses para deixar de 
aplicar uma lei são: (1) inconstitucionalidade; (2) resolução de antinomias; (3) interpretação conforme a constituição; (4) nulidade parcial sem redução de texto; (5) inconstitucionalidade com redução de texto; (6) deixar de aplicar uma regra em face de um princípio, como no exemplo de deixar de aplicar a regra do furto em razão da insignificância (STRECK, 2017).

As três perguntas fundamentais são: (1) há a presença de direito fundamental?; (2) posso decidir do mesmo modo para todos os casos similares?; (3) posso transferir recursos dos outros em situações idênticas para atender esse caso? E os cinco padrões interpretativos fundamentais são: (1) autonomia do direito; (2) controle hermenêutico da interpretação; (3) respeito à integridade e à coerência do direito; (4) dever fundamental de justificar e fundamentar as decisões; (5) direito fundamental a obtenção de respostas corretas constitucionalmente adequadas. Em suma, a decisão jurídica precisa encontrar uma conformação mais englobante (prescritiva) com critérios que lhe dê legitimidade e uma forma de avaliação (como será a decisão amanhã?) (STRECK, 2017b).

A teoria da decisão elaborada pela crítica hermenêutica do direito apresenta critérios passíveis de serem utilizados tanto por quem tem o dever de decidir (juízes, por exemplo), como por aqueles que têm o dever de avaliar a decisão de quem decide (por exemplo, a doutrina). Portanto, pode e deve ser usada para analisar as decisões dos juízes. Além disso, sem esquecer o fundamento filosófico que embasa tal empreendimento doutrinário, ou seja, o paradigma hermenêutico de Heidegger e de Gadamer, por um lado, juntamente com o interpretativismo de Dworkin, por outro, impõem limites à discricionariedade. Como foi apresentado, Dworkin, Gadamer, Heidegger e a crítica hermenêutica do direito têm a pretensão de apresentar o intérprete num contexto muito maior do que ele próprio e que, ao mesmo tempo, serve tanto de condição, quanto de limite da interpretação.

\section{CONCLUSÃO}

Todas as disputas em torno do fundamento da filosofia estão presentes na teoria do direito e na filosofia do direito. Discutir ética, política e direito, hoje, significa, mesmo que inconscientemente, posicionar-se de algum modo sobre os fundamentos que a tradição da filosofia nos transmite, nos impõe. Não por acaso, o senso comum teórico dos juristas fica, quando não misturando, pulando de fundamento em fundamento, ora antigo-objetivo, ora moderno-subjetivo. 
Tal comportamento de mistura de fundamentos e métodos fica claro nos modelos hermenêuticos. No dedutivo, predomina a objetividade. No decisionista, predomina a subjetividade. O modelo discricionário fica no meio dessa relação sujeito-objeto, sendo que, na falha da objetividade, apela-se à subjetividade discricionária, marcando o déficit histórico do positivismo no tratamento da interpretação e da decisão.

Quanto aos positivismos, desde o utilitarista de Bentham até o positivismo normativo, vimos que, muito embora suas versões variem ao longo do tempo, alguns elementos permanecem em comum. A ênfase na descrição analítica, a distinção entre direito e moral e o relativismo acabam levando, inevitavelmente, à discricionariedade. Isso acontece desde a versão mais fechada, a exclusiva, até a mais aberta, a inclusiva. Se esses elementos em comum estão em todos os positivismos, será que as "novas" versões são novas mesmo? Concluimos que não.

Nesse sentido, a crítica hermenêutica do direito e seu método fenomenológico de desvelar o que está velado são úteis para compreendermos o imaginário jurídico positivista do senso comum teórico, no qual descrição teórica para identificar o direito, neutralidade, relativismo, ceticismo quanto aos valores e separação radical entre direito e moral acabam sendo úteis na ciência do direito em sua parte dogmática, resultando no extremo da objetividade, mas, na teoria da decisão, acaba na discricionariedade, resultando no extremo da subjetividade.

No entanto, a crítica hermenêutica não é apenas negativa e desconstrutiva com relação aos positivismos, ela é também propositiva e construtiva de uma teoria da decisão com seus critérios de coerência e de integridade, os quais apresentam o intérprete num contexto muito maior do que ele próprio (tradição, comunidade) e que serve, ao mesmo tempo, tanto de condição, como de limite da interpretação.

Para finalizar, constantemente no direito temos que realizar a escolha entre sermos ouriços ou raposas (STRECK, 2017b). As raposas sabem pouco de muitas coisas e localizamse na foz dos rios. Os ouriços sabem uma única coisa, buscando a nascente dos rios. No direito, muitas vezes, a distração é tanta com a foz dos rios, que se esquece de buscar suas nascentes. A questão fundamental da filosofia no direito é, justamente por ser fundamental, ir lá no fundo, lá na origem, lá onde as coisas se (a) fundam, lá na raíz radical de todas elas e, então, mostrar seus fundamentos ("arché"), para que adquiram novas compreensões. Procuramos fazer isso com a tradição do positivismso jurídico: mostrar os limites de seus fundamentos filosóficos. Na esperança de que niguém se banha no mesmo rio duas vezes, 
espero que mergulhemos no positivismo de outra forma, conhecendo seus fundamentos e compreendendo, interpretando e decidindo melhor.

\section{REFERÊNCIAS}

BARZOTTO, Luis Fernando. O positivismo jurídico contemporâneo: uma introdução à Kelsen, Ross e Hart. São Leopoldo: UNISINOS, 2004.

BOBBIO, Norberto. O positivismo jurídico. Lições de filosofia do direito. São Paulo: Ícone, 1995.

CALVO GARCIA, Manuel. Los fundamentos del metodo jurídico: una revisión crítica. Madrid: Tecnos, 1994.

D'AGOSTINI, Franca. Analíticos e continentais: guia à filosofia dos últimos trinta anos. São Leopoldo: Unisinos, 2002.

DWORKIN, Ronald. O império do direito. 3.ed. São Paulo: MArtins Fontes, 2014.

FARALLI, Carla. A filosofia do direito contemporânea. São Paulo: Martins Fontes, 2006.

GADAMER, Hans Georg. Verdade e método: traços fundamentais de uma hermenêutica filosófica. 2.ed.

Petrópolis: Vozes, 1998.

GARCIA-ROZA, Luiz Alfredo. Palavra e verdade: na filosofia antiga e na psicanálise. Rio de Janeiro. J. Zahar, 1990.

GILSON, Etienne. A filosofia na Idade Média. São Paulo: Martins Fontes, 2001.

GOYARD-FABRE, Simone. Os princípios filosóficos do direito político moderno. São Paulo: Martins Fontes, 1999.

GHIRALDELLI JÚNIOR, Paulo. A aventura da filosofia. São Paulo, Manole, 2010.

HABERMAS, Jürgen. O discurso filosófico da modernidade: doze lições. São Paulo: Martins Fontes, 2002.

HEIDEGGER, Martin. Ensaios e conferências. Petrópolis: Vozes, 2001.

HEIDEGGER, Martin. Ser y tiempo. Madrid: Trotta, 2003.

HOTTOIS, Gilbert. Do Renascimento à pós-modernidade: uma história da filosofia moderna e contemporânea. São Paulo: Idéias \& Letras, 2008.

KAUFMANN, Arthur. La filosofía del derecho en la posmodernidad. Bogotá: Temis, 1992.

KUSCH, Martin. Language as calculus vs. language as universal medium: a study in Husserl, Heidegger and Gadamer. Dordrecht: Kluwer Academic, 1989.

LIPOVETSKY, Gilles; SERROY, Jean. A cultura-mundo: resposta a uma sociedade desorientada. São Paulo: Companhia das Letras, 2001.

LOSANO, Mario. Sistema e estrutura no direito. São Paulo: Martins Fontes, 2011.

MACCUMBER, John. Metaphysics and opression: Heidegger's challenge to western philosophy. Blomington: Indiana Press University, 1999.

MORRISON, Wayne. Filosofia do Direito. São Paulo: Martins Fontes, 2006. 
PALMER, Richard E. Hermenêutica. Lisboa: Edições 70, 1989.

PHILIPPI, Jeanine Nicolazzi. A lei: uma abordagem a partir da leitura cruzada entre direito e psicanálise. Belo Horizonte: Del Rey, 2001.

REALE, Giovanni; ANTISERI, Dario. Historia del pensamiento filosófico y científico. 2.ed. Barcelona: Herder, 1995

ROHDEN, Luiz; KUSSLER, Leonardo Marques. Pressuposto ético da alteridade na hermenêutica filosófica à luz do Sofista de Platão. Trans/Form/Ação, Marília, v. 44, n. 3, p. 257-276, Jul./Set., 2021.

SCHMIDT, Lawrence K. Hermenêutica. Petrópolis: Vozes, 2012.

STEIN, Ernildo. Epistemologia e crítica da modernidade. 3.ed. Ijuí: UNIJUÍ, 2001.

STEIN, Ernildo. Pensar é pensar a diferença: filosofia e conhecimento empírico. Ijuí: Unijuí, 2002.

STEIN, Ernildo. Compreensão e finitude: estrutura e movimento da interrogação heideggeriana. Ijuí: UNIJUÍ, 2000.

STRECK, Lenio Luiz. Hermenêutica jurídica e(m) crise: uma exploração hermenêutica da construção do direito. 11. ed., rev. atual. e ampl. Porto Alegre: Livraria do Advogado, 2014.

STRECK, Lenio Luiz. Verdade e consenso: constituição, hermenêutica e teorias discursivas. 6.ed. São Paulo: Saraiva, 2017.

STRECK, Lenio Luiz. Hermenêutica e jurisdição: diálogos com Lenio Streck. Porto Alegre: Livraria do Advogado, 2017b.

STRECK, Lenio Luiz. O que é isto - o senso incomum? Porto Alegre: Livraria do Advogado, 2017c.

STRECK, Lenio Luiz. Dicionário de hermenêutica: quarenta temas fundamentais da teoria do direito à luz da crítica hermenêutica do direito. Belo Horizonte: Letramento, 2017d.

STRECK, Lenio Luiz (et. al.) (Coords.). Hermenêutica e jurisprudência no Código de Processo Civil: coerência e integridade. 2.ed. São Paulo: Saraiva Educação, 2018.

TATIÁN, Diego. Desde la línea. Dimensión politica en Heidegger. Córdoba: Alción, 1997.

TEIXEIRA, Evilázio. Modernidade e pós-modernidade: luzes e sombras. Cadernos IHU Idéias, São Leopoldo, v.4, n.50, p.1-21, 2006.

VATTIMO, Gianni. Pósfácio: o fim da filosofia na idade da democracia. In PECORARO, Rossano. Niilismo e pós-modernidade. São Paulo: Loyola, 2005.

VATTIMO, Gianni. O fim da modernidade: niilismo e hermenêutica na cultura pós-moderna. São Paulo: Martins Fontes, 1996.

VATTIMO, Gianni. Posmodernidad, In ORTIZ-OSÉS, Andrés; LANCEROS, Patxi. Diccionário interdisciplinar de hermenéutica. Bilbao: Universidad de Deusto, 2004, p.433-436.

VERBICARO, Loiane Prado. Judicialização da política, ativismo e discricionariedade judicial. 2.ed. Rio de Janeiro: Lumen Juris, 2019.

VILLEY, Michel. A formação do pensamento jurídico moderno. São Paulo: Martins Fontes, 2009.

WARAT, Luís Alberto; PEPÊ, Albano Marcos Bastos. Filosofia do direito: uma introdução crítica. São Paulo: Moderna, 1996. 
WARAT, Luís Alberto. A Ciência Jurídica e Seus Dois Maridos. In WARAT, Luís Alberto. Territórios Desconhecidos: a procura surrealista pelos lugares do abandono do sentido e da reconstrução da subjetividade. Santa Cruz do Sul: EDUNISC, 2000. p.61-186.

WARAT, Luiz Alberto. O senso comum teórico dos juristas. In SOUSA JÚNIOR, José Geraldo de (Org.). Introdução crítica ao direito. Brasília: EDUNB/CEAD, 1993, p.101-104.

WOLKMER, Antonio Carlos. Síntese de uma história das idéias jurídicas: da antigüidade clássica à modernidade. 2.ed. Florianópolis: Boiteux, 2008.

ZANIN, Fabrício Carlos. Crise da modernidade e organização técnica do trabalho, do consumo e da cidade. In Revista da Faculdade de Direito de Guanambi, 2018, Disponível em:

<http://revistas.faculdadeguanambi.edu.br/index.php/Revistadedireito/article/view/224>.

ZANIN, Fabrício Carlos; POLICARPO, Douglas. Direitos humanos como fundamento de uma cultura de paz, cidadania e justiça: desafios brasileiros entre modernidade e pós-modernidade. In SALATINI, Rafael; PAZÓ, Cristina Grobério; POLICARPO, Douglas (Orgs.). Justiça e cidadania: reflexões sobre o campo normativo moderno. Dourados: UFGD, 2014, p.79-114.

ZANIN, Fabrício Carlos; COSTA, Paulo Sérgio Weyl Albuquerque. Hermes é brasileiro: metafísica, hermenêutica jurídica e exceção. In. XXVIII Congresso Nacional do CONPEDI, Goiânia. Anais do XXVIII Congresso Nacional do CONPEDI, 2019. 